\title{
Banishing Biases to Save Lives: Introducing Genetic Testing for Familial Cancers
}

\begin{abstract}
Beatriz Marcheco Teruel MD PhD
Malignant tumors are the second cause of death in Cuba and the first cause of years of potential life lost. Over the last 40 years, cancer mortality rates have multiplied by 5 for prostate, 4 for colon and 3.4 for breast.[1]
\end{abstract}

In cancers whose responsible genetic mutation has been identified, predictive genetic studies can be key to early diagnosis and prevention for individuals and their families for generations to come. Such is the case for breast and colon cancers, for which laboratory tests can determine predisposition, anticipating cancers before symptoms appear.

In Cuba, we have the wherewithal to perform these tests at the National Medical Genetics Center. Since 2004, trained genetics counselors also work in primary health care, developing registries for three cancer sites: breast, colon and prostate. In the country's some 450 polyclinics, they collaborate closely with family doctors and nurses to update the registries for research purposes and, above all, to permit early diagnosis and prevention for families at risk in the polyclinics' geographic catchment areas.

For all genetically-associated illnesses addressed by these counselors, tracing the condition along the family tree is an essential tool. Its use is aided by high literacy and educational levels in Cuba's population, and the public trust built over time that permits fluid communication between family members and health professionals.

However, counselors can hit a stone wall when it comes to family histories of cancer. Why? Because the disease is still stigmatized, patients are often surrounded by a "culture of silence" in which relatives, physicians and even patients themselves are complicit. Frequently, family members and attending physicians still hide the diagnosis from the person who is ill; and, incredible as it may seem after receiving surgery, chemotherapy and radiation treatments, patients too may act as if they are simply unaware.

This silence makes it extremely difficult for genetics counselors to have open discussions with families about relatives who have suffered cancer. This in turn not only hampers early-potentially lifesaving - diagnosis, but also leaves physicians' hands tied, unable to recommend preventive, lifestyle changes to mitigate risk. So, while our universal public health system and its scientific capacities could save them, people die unnecessarily.

How to reverse this situation? First, systematically educating health professionals themselves, from early in their training through specialization, about the field of genetics and its potential, including DNA research, and about the need to be more open and forthright with cancer patients and their families; and giving them the tools to provide both preventive and followup care, including psychological counseling, to families and individuals either at risk or ill.
Second, greater public education about cancer; about individual and family responsibilities for taking care of their own health; and about the need for them to exercise their right to know about their own and their family's risks of developing cancer, preparing them to interpret as well as to manage the options available in the health system. Schools as well as the media have key roles to play in this process aimed at reversing a cultural bias-with television, radio and newspapers taking full advantage of the population's high educational levels.

Third, we need to be aware of and implement all methods at our disposal for early diagnosis and followup with secondary prevention and appropriate treatment. We have the human resources and technological infrastructure to do this within our pharmaceutical and R\&D centers, which have produced drugs of proven efficacy.

\section{As with so many other illnesses, science alone cannot save lives. It takes a cultural shift, and the time is now}

The National Medical Genetics Center is ready and able to introduce predictive genetic testing for breast and colon cancers in families with histories of these diseases-pre-symptomatic molecular diagnosis of the most frequent forms of familial breast cancer, and hereditary nonpolyposis colorectal cancer and familial adenomatous polyposis.

However, such testing is predicated on the real possibility of genetic counselors, including family doctors specially trained in genetics, building accurate registries among at-risk families in the communities they serve.

As with so many other illnesses, science alone cannot save lives. It takes a cultural shift, and the time is now. -1 .

1. National Health Statistics and Medical Records Division (CU). Anuario Estadístico de Salud 2010 [Internet]. Havana: Ministry of Public Health (CU); 2011 [cited 2012 Jan 24]. Available from: http://files.sld.cu/dne/files/2011/04/ anuario-2010-e-sin-graficos1.pdf. Spanish. 174 p.

Submitted: February 10, 2012

Approved for publication: October 21, 2012

Disclosures: None 